\title{
Clinico-Laboratory Features and Associated Factors of Lupus Mesenteric Vasculitis
}

Hongxu Wang · Qing Gao · Guanyi Liao · Sirui Ren · Wenxian You

Received: February 22, 2021 / Accepted: May 13, 2021 / Published online: May 29, 2021

(C) The Author(s) 2021

\section{ABSTRACT}

Introduction: Lupus mesenteric vasculitis (LMV) is a rare but potentially life-threatening clinical entity in systemic lupus erythematosus (SLE) patients.

Objective: The present study was initiated to explore the clinical features and associated factors of LMV in SLE patients.

Methods: We conducted a retrospective study on 50 cases of SLE patients with lupus mesenteric vasculitis (LMV) from January 2010 to December 2019 and 89 cases of non-LMV-SLE

\footnotetext{
H. Wang

Department of Laboratory Medicine, The First Affiliated Hospital of Chongqing Medical University, Chongqing 400016, China

e-mail: wanghx502@163.com

Q. Gao · G. Liao · W. You $(\bowtie)$

Department of Gastroenterology, The First Affiliated

Hospital of Chongqing Medical University, Chongqing 400016, China

e-mail: fs_ywx@163.com

Q. Gao

e-mail: 981051852@qq.com

G. Liao

e-mail: 784135487@qq.com

S. Ren

Department of Intensive Care Unit, The First

Affiliated Hospital of Chongqing Medical

University, Chongqing 400016, China

e-mail: 617988313@qq.com
}

patients with similar demographic and comorbidities were included as control. All the data regarding clinical features, laboratory findings, and treatment were reviewed independently by two experts in the field. Both univariate and multivariate logistic regression analyses were employed to identify the associated factors of LMV.

Results: The incidence of LMV was $2.9 \%$ among hospitalized SLE patients in the current study. The most frequent symptom and physical sign of LMV were respectively abdominal pain $(48,96 \%)$ and abdominal tenderness (45, 90\%). Through univariate and subsequent multivariate analysis, oral ulcer (OR, 4.25; $P=0.024)$, urinary tract involvement $(\mathrm{OR}, 5.23$; $P=0.021)$, and elevated D-dimer (OR, 1.121; $P=0.008$ ) were demonstrated to be positively associated with LMV, while percentage of lymphocytes (OR, 0.928; $P=0.004$ ) and complement $3(\mathrm{OR}, 0.048 ; P=0.008)$ were negatively correlated with LMV.

Conclusions: Oral ulcer, urinary tract involvement, reduced percentage of lymphocytes and complement 3, elevated D-dimer could be associated factors for LMV in SLE patients.

Keywords: Systemic lupus erythematosus; Lupus mesenteric vasculitis; Associated factors; Oral ulcer; Urinary tract involvement; Percentage of lymphocytes; C3; D-dimer 


\section{Key Summary Points}

\section{Why conduct this study?}

Mesenteric vasculitis is a rare but potentially life-threatening clinical entity in SLE patients. The heterogeneity and lack of comprehensive understanding of LMV made prompt and accurate diagnosis of LMV a big challenge.

Hence, this study aimed to explore the clinico-laboratory features and associated factors of LMV.

\section{What was learned from the study?}

The most frequent symptom and physical sign of LMV were respectively abdominal pain and abdominal tenderness.

Most of the LMV patients could achieve clinical remission after appropriate treatment.

Oral ulcer, urinary tract involvement, reduced percentage of lymphocytes and complement 3, and elevated D-dimer could be associated factors of LMV in SLE patients.

\section{DIGITAL FEATURES}

This article is published with digital features, including a summary slide, to facilitate understanding of the article. To view digital features for this article go to https://doi.org/10.6084/ m9.figshare.14579568.

\section{INTRODUCTION}

Systemic lupus erythematosus (SLE) is an autoimmune inflammatory disease characterized by the loss of self-tolerance and formation of nuclear auto-antigens and immune complexes, and may virtually attack every organ [1]. Lupus mesenteric vasculitis (LMV) is a rare but serious complication of SLE patients [2]. Severe bowel ischemia caused by LMV could lead to life-threatening bowel infarction and perforation [3-5]. LMV is also the leading cause of acute abdominal pain in SLE patients [6]. Abdominal computed tomography (CT) scans with contrast could provide pivotal diagnostic information for LMV [7, 8]. However, its heterogeneous presentations complicated the prompt and accurate diagnosis of LMV [9]. Several clinical retrospective studies have been carried out on clinical features $[6,10,11]$ and associated factors for the recurrence and prognosis of LMV [11]. However, the clinical study on LMV in southwest of China is still limited. Thus, the present study was initiated to explore the clinical features and associated factors of LMV in SLE patients.

\section{METHODS}

\section{Patients and Setting}

Fifty cases of LMV patients and 89 cases of nonLMV-SLE patients that were admitted to the First Affiliated Hospital of Chongqing Medical University from January 2010 to December 2019 were enrolled in the current study. The contemporaneous non-LMV-SLE patients had similar demographic characteristics, with common SLE symptoms such as rash and arthralgia as chief complaints, but without LMV. They were randomly selected in control group. Medical records including clinical features, laboratory findings, and treatment were reviewed independently by two experts in the field. This study was performed in accordance with the Helsinki Declaration of 1964, and its later amendments. This retrospective study was reviewed and approved by the Ethics Committee of The First Affiliated Hospital of Chongqing Medical University. For this type of study, formal consent is not required.

\section{Diagnostic Criteria}

LMV was defined as: (1) clinical evidence of multifocal bowel or multiple vascular territories 
involvement, duodenal ischemic changes, bowel wall thickening [12, 13], and clinical improvement when treated with intravenous steroid or immunosuppressant $[14,15]$; or (2) pathological verification of vasculitis changes or satisfaction of at least three of the following signs demonstrated by abdominal computed tomography (CT) - bowel wall thickening, target sign, dilatation of intestinal segments, engorgement of mesenteric vessels, and increased attenuation of mesenteric fat [12].

SLE was diagnosed according to the 2010 revised Chinese Rheumatology Association (CRA) revised classification criteria [16, 17]. Meanwhile, patients with antiphospholipid syndrome were excluded.

Oral ulcer was defined as painless and nonspecific oral mucosal erosion. Only oral ulcers occur within 3 months of the flare stage of LMV and/or SLE were included. Additionally, oral ulcers caused by drugs, microbial infection, and mechanical damage were excluded in the current study.

Lupus nephritis (LN) was defined if clinical and laboratory manifestations met the ACR criteria [18]. Lupus urinary tract involvement means the following signs were identified by ultrasonography/abdominal CT: stenosis/dilatation of the ureters, bladder wall thickening, and hydroureteronephrosis. Meanwhile, urinary tract involvement caused by non-SLE related factors such as infection, urinary calculus, malignancy, neuropathy, and side effects of medication were ruled out. Remission of LMV was defined as disappearance of gastrointestinal manifestations or improvement of bowel wall edema confirmed by CT scan.

\section{Study Variables}

Clinico-laboratory information of LMV and SLE was extracted from clinical records. If the data of an indicator were missing, we evaluated the importance of the indicator, and analyzed the normality of the index data. Firstly, if the missing data is of importance, we discarded the case. If the data of the indicator are normal, we would use its mean to replace the missing data. Otherwise, we would replace missing data with the median. Systemic lupus erythematosus disease activity index 2000 (SLEDAI-2K) was employed to evaluate SLE [19].

\section{Statistical Analysis}

Variables were presented as median (interquartile range) (median (IQR)) and categorical data was outputted as the absolute count and percentage.

Statistical analyses in the current study were conducted using SPSS Statistical Software version 22.0 (SPSS Inc., Chicago, IL, USA). First, each variable was separately evaluated using univariate analysis. The differences of continuous variables were compared using Wilcoxon rank-sum test (non-normally distributed variables). Meanwhile, a Chi-square test or Fisher's exact test was employed to compare the differences of categorical variables. The odds ratio (OR) and 95\% confidence interval (CI) were obtained to evaluate the degree of any correlation. Furthermore, variables with $P<0.1$ in prior comparisons were included in the stepwise multivariate logistic regression analysis. Logistic regression was performed via enter method. $P<0.05$ was considered to be statistically significant for all calculations.

\section{RESULTS}

\section{Clinical Features of Lupus Mesenteric Vasculitis (LMV)}

\section{Clinical Manifestations of LMV}

Among all the 1724 SLE patients admitted to our hospital during 2010-2019, 50 patients were diagnosed as LMV, with a $2.9 \%$ incidence. The 50 LMV patients had an SLE duration (median (interquartile range)) of 10 (3-90) days, with LMV being the initial presentation of SLE in 13 patients. The most frequent symptom and physical sign were abdominal pain $(48,96 \%)$ and abdominal tenderness $(45,90 \%)$, respectively. Most patients $(31 / 48,64.58 \%)$ suffered from acute, persistent, and diffuse abdominal pain, and the remaining $17(17 / 48,35.42 \%)$ patients experienced paroxysmal or 
Table 1 Clinical characteristics of 50 patients with lupus mesenteric vasculitis (LMV)

\begin{tabular}{ll}
\hline Features & LMV $(\boldsymbol{N}=\mathbf{5 0})$ \\
\hline SLE duration, day, median (IQR) & $10(3-90)$ \\
Abdominal pain, $n$ (\%) & $48(96.0)$ \\
Abdominal distension, $n$ (\%) & $43(86.0)$ \\
Diarrhea, $n$ (\%) & $29(58.0)$ \\
Nausea, $n$ (\%) & $42(84.0)$ \\
Vomiting, $n$ (\%) & $34(68.0)$ \\
Alimentary tract hemorrhage, $n(\%)$ & $11(22.0)$ \\
Abdominal tenderness, $n(\%)$ & $45(90.0)$ \\
Intestinal obstruction, $n$ (\%) & $7(14.0)$ \\
Intestinal perforation, $n$ (\%) & $1(2.0)$ \\
Lupus urinary tract involvement, $n(\%)$ & $16(32.0)$ \\
\hline
\end{tabular}

$I Q R$ interquartile range, $N$ number, $S L E$ systemic lupus erythematosus, $L M V$ lupus mesenteric vasculitis

intermittent pain. When concerned with pain intensity, the patients complained of mild (20/ $48,41.67 \%)$, moderate $(21 / 48,43.75 \%)$, and severe $(7 / 48,14.58 \%)$ abdominal pain. Only 2 patients complained of abdominal distension and fatigue without abdominal pain. Besides, abdominal distension (43, 86\%), nausea (42, $84 \%)$, vomiting $(34,68 \%)$, and diarrhea (29, $58 \%$ ) were common manifestations in LMV patients. Additionally, 7 LMV patients (7/50, $14 \%$ were complicated with intestinal obstruction (Table 1).

Apart from impairment of digestive system itself, LMV was usually accompanied by concurrent damage to other organs. Among the 50 LMV patients, $16(32.0 \%)$ demonstrated lupus urinary tract involvement, mainly presenting as bladder irritation symptoms and dysuria (Table 1). A close review of the diagnostic process found that many patients were admitted as abdominalgia yet to be investigated. Due to non-specific manifestation of LMV, many patients were admitted to un-appropriate departments and initially misdiagnosed as acute gastroenteritis (9/50), intestinal tuberculosis/ peritoneal tuberculosis $(5 / 50)$, urinary tract
Table 2 Abdominal CT findings of 50 lupus mesenteric vasculitis (LMV) patients

\begin{tabular}{lll}
\hline Features & Number & Percentage \\
\hline $\begin{array}{l}\text { Engorgement of mesenteric } \\
\quad \text { vessels }\end{array}$ & 50 & 100 \\
Bowel wall thickening & 49 & 98 \\
$\begin{array}{l}\text { Increased attenuation of } \\
\quad \text { mesenteric fat }\end{array}$ & 44 & 88 \\
Ascites & 32 & 64 \\
Target sign & 35 & 70 \\
Comb sign & 21 & 42 \\
Dilatation of intestinal segments & 11 & 22 \\
Intestinal segment being involved & & \\
Jejunum and ileum & 19 & 38 \\
Colon and rectum & 8 & 16 \\
Both small and large intestine & 22 & 44 \\
Hydroureteronephrosis & 10 & 20 \\
Stenosis/dilatation of the ureters & 8 & 16 \\
Bladder wall thickening & 7 & 14 \\
\hline
\end{tabular}

infection/urinary calculi (4/50), pancreatitis (4/ $50)$, and hepatitis (3/50).

\section{Imaging Features of LMV}

Abdominal CT (computed tomography) scan could provide essential evidence to make an accurate diagnosis of LMV. Table 2 demonstrated the imaging features of abdominal CT in LMV patients. Abdominal CT revealed engorgement of mesenteric vessels (50/50, $100 \%)$, bowel wall thickening (49/50,98\%), and increased attenuation of mesenteric fat (44/50, $88 \%)$. "Target sign" and "comb sign", as the well-acknowledged and classical features of LMV, were noted in 35(70\%) and 21(42\%) LMV patients, respectively. Meanwhile, dilatation of bowel segments was observed in 11 patients, and $64 \%$ of LMV patients (32/50) experienced ascites. Although jejunum and ileum (41/50, $82 \%$ ) were the predilection sites of LMV, impairment was not limited to small intestine. 
Table 3 Comparison of demographic and clinical features between LMV and SLE patients

\begin{tabular}{llll}
\hline Features & LMV & SLE & P value \\
\hline Male/female, $N$ (\%) & $2 / 48$ & $9 / 80$ & 0.200 \\
Age(year), median (IQR) & $41(26.0-51.5)$ & $40.5(26.75-50.0)$ & 0.787 \\
SLEDAI, median (IQR) & $16(12-18.25)$ & $11(8-14.5)$ & $0.001^{\dagger}$ \\
Weight loss, $N$ (\%) & $14(28.0)$ & $11(12.4)$ & $0.021^{\dagger}$ \\
Skin rash, $N$ (\%) & $25(50.0)$ & $29(32.6)$ & $0.043^{\dagger}$ \\
Arthritis, $N(\%)$ & $23(46.0)$ & $50(56.2)$ & 0.249 \\
Neurologic involvement, $N(\%)$ & $5(10.0)$ & $13(14.6)$ & 0.438 \\
Oral ulcers, $N(\%)$ & $19(38.0)$ & $12(13.5)$ & $0.001^{\dagger}$ \\
Alopecia, $N(\%)$ & $22(44.0)$ & $23(25.8)$ & $0.028^{\dagger}$ \\
Fever, $N$ (\%) & $15(30.0)$ & $31(34.8)$ & 0.561 \\
Fatigue, $N(\%)$ & $31(62.0)$ & $38(42.7)$ & $0.029^{\dagger}$ \\
Myositis (\%) & $11(22.0)$ & $17(19.10)$ & 0.421 \\
Edema, $N(\%)$ & $7(14.0)$ & $7(7.9)$ & 0.249 \\
LN, $N(\%)$ & $29(58.0)$ & $42(47.2)$ & 0.289 \\
Lupus urinary tract involvement, $N(\%)$ & $16(32.0)$ & $8(9.0)$ & $0.001^{\dagger}$ \\
\hline
\end{tabular}

SLEDAI Systemic Lupus Erythematosus Disease Activity Index, IQR interquartile range, $N$ number, $S L E$, systemic lupus erythematosus, $L M V$, lupus mesenteric vasculitis

$\dagger$ Represents $P \leq 0.05$

In all, $60 \%$ of LMV patients (30/50) suffered large intestinal lesion of lupus. Additionally, 16 LMV patients had lupus urinary tract involvement, including hydroureteronephrosis $(10 / 16$, $62.5 \%)$, stenosis/dilatation of the ureters $(8 / 16$, $50.0 \%)$, and bladder wall thickening $(7 / 16$, $43.75 \%)$.

\section{Treatment and Outcomes}

Fifty patients with LMV received administration of glucocorticoid, and the dosage of glucocorticoid was adjusted dynamically or combined with other drugs according to their state of illness. While two patients with LMV died during hospitalization because of life-threatening intestinal perforation and severe nervous system impairment, the other 48 (96\%) LMV patients achieved clinical remission after appropriate treatment. Among them, 15 patients were treated with prednisone (0.5-1 $\mathrm{mg} / \mathrm{kg}$ days) or methylprednisone alone, and 17 patients were treated with prednisone combined with antimalarial drugs with a dosage mentioned above. In addition, seven patients were administrated to pulse therapy with methylprednisone (1000 mg qd) for 3-4 days because of insufficient relief of symptoms after conventional dosage of prednisone for 3-7 days. Three cases received pulse therapy of methylprednisolone with $1000 \mathrm{mg} /$ days for 3 days, and one of the patients was also given a single dose of cyclophosphamide $600 \mathrm{mg}$. Another six patients were treated with oral and conventional dose of prednisone plus azathioprine or methotrexate. 
Table 4 Comparison of laboratory indexes between LMV and SLE patients

\begin{tabular}{|c|c|c|c|c|}
\hline Index & LMV & SLE & Normal range & $P$ value \\
\hline $\begin{array}{l}\text { WBC }\left(\times 10^{9}\right) \\
\text { median }(\mathrm{IQR})\end{array}$ & $4.68(3.33-7.52)$ & $4.13(2.90-6.5)$ & $3.5-9.5$ & 0.431 \\
\hline $\begin{array}{l}\mathrm{HGB}(\mathrm{g} / \mathrm{l}) \text {, median } \\
\text { (IQR) }\end{array}$ & $\begin{array}{l}112.0 \\
\quad(90.0-131.0)\end{array}$ & $\begin{array}{l}100.50 \\
\quad(84.0-119.0)\end{array}$ & $\begin{array}{l}115.0-150.0(\mathrm{~F}) \\
130.0-170.0(\mathrm{M})\end{array}$ & $0.022^{\dagger}$ \\
\hline $\begin{array}{l}\operatorname{PLT}\left(\times 10^{9}\right), \text { median } \\
(\mathrm{IQR})\end{array}$ & $\begin{array}{l}167.5 \\
(116.5-222.25)\end{array}$ & $\begin{array}{l}126 \\
(84-237.75)\end{array}$ & $\begin{array}{l}101-320(\mathrm{~F}) \\
85-303(\mathrm{M})\end{array}$ & 0.255 \\
\hline N\%, median (IQR) & $\begin{array}{l}76.10 \\
\quad(70.15-85.90)\end{array}$ & $\begin{array}{l}70.15 \\
\quad(62.65-76.30)\end{array}$ & $40.0-75.0$ & $0.002^{\dagger}$ \\
\hline L\%, median (IQR) & $\begin{array}{l}15.0 \\
(8.90-20.55)\end{array}$ & $\begin{array}{l}21.35 \\
\quad(16.80-27.20)\end{array}$ & $20.0-50.0$ & $<0.001^{\dagger}$ \\
\hline Pyuria, $N(\%)$ & $22(44.0)$ & $30(33.71)$ & $\mathrm{WBC} / \mathrm{HPF} \leq 5$ & 0.154 \\
\hline Hematuria, $N(\%)$ & $18(36.0)$ & $22(24.72)$ & $\mathrm{RBC} / \mathrm{HPF} \leq 5$ & 0.113 \\
\hline Proteinuria, $N(\%)$ & $17(34.0)$ & $19(21.35)$ & Urinary protein $(24 \mathrm{~h}) \leq 500 \mathrm{mg}$ & 0.077 \\
\hline ANA $(+), N(\%)$ & $49(98.0)$ & $89(100.0)$ & $<1: 100$ & 0.360 \\
\hline $\begin{array}{l}\text { Anti-dsDNA Ab } \\
\quad(+), N(\%)\end{array}$ & $31(62.0)$ & $54(60.7)$ & $<100 \mathrm{IU} / \mathrm{ml}$ & 0.878 \\
\hline SSA, $N(\%)$ & $39(78.0)$ & $52(58.4)$ & Negative & $0.020^{\dagger}$ \\
\hline $\begin{array}{l}\mathrm{C} 3 \text {, median }(\mathrm{IQR}) \\
(\mathrm{g} / \mathrm{l})\end{array}$ & $0.36(0.23-0.45)$ & $\begin{array}{l}0.42 \\
\quad(0.31-0.57)\end{array}$ & $0.79-1.52$ & $0.007^{\dagger}$ \\
\hline $\begin{array}{l}\text { C4, median (IQR) } \\
(\mathrm{g} / \mathrm{l})\end{array}$ & $0.06(0.03-0.11)$ & $\begin{array}{l}0.10 \\
\quad(0.05-0.14)\end{array}$ & $0.16-0.38$ & $0.017^{\dagger}$ \\
\hline $\begin{array}{l}\text { IgG, median (IQR) } \\
\quad(\mathrm{g} / \mathrm{l})\end{array}$ & $\begin{array}{l}16.10 \\
\quad(11.75-20.70)\end{array}$ & $\begin{array}{l}19.90 \\
\quad(16.33-26.03)\end{array}$ & $7.51-15.60$ & $<0.001^{\dagger}$ \\
\hline $\begin{array}{l}\text { D-D, median (IQR) } \\
(\mathrm{mg} / \mathrm{l})\end{array}$ & $3.83(1.12-8.24)$ & $\begin{array}{l}1.24 \\
\quad(1.00-4.67)\end{array}$ & $0-0.55$ & $<0.001^{\dagger}$ \\
\hline $\begin{array}{l}\text { ESR, median } \\
\qquad(\mathrm{IQR})(\mathrm{mm} / \mathrm{h})\end{array}$ & $\begin{array}{l}55.5 \\
\quad(14.75-91.0)\end{array}$ & $59(33.75-84.0)$ & $\begin{array}{c}2-43, \mathrm{M}, \mathrm{A}>60 ; 2-21, \mathrm{M}, \mathrm{A} \leq 60 \\
2-38, \mathrm{~F}, \mathrm{~A}>50 ; 2-26, \mathrm{~F}, \mathrm{~A} \leq 50\end{array}$ & $0.01^{\dagger}$ \\
\hline $\begin{array}{l}\text { CRP, median (IQR) } \\
(\mathrm{mg} / \mathrm{l})\end{array}$ & $\begin{array}{l}33.62 \\
\quad(10.68-88.86)\end{array}$ & $\begin{array}{l}20.10 \\
\quad(11.73-30.5)\end{array}$ & $<10$ & 0.237 \\
\hline $\begin{array}{l}\text { Anticardiolipin } \mathrm{Ab} \\
\text { (RU/ml) }\end{array}$ & $3.24(0.81-9.84)$ & $\begin{array}{l}9.95 \\
\quad(8.11-14.57)\end{array}$ & 4.20 & $0.002^{\dagger}$ \\
\hline $\begin{array}{l}\text { Cre, median (IQR) } \\
\quad(\mu \mathrm{mol} / \mathrm{l})\end{array}$ & $\begin{array}{l}73.50 \\
\quad(46.75-107.75)\end{array}$ & $\begin{array}{l}59.0 \\
\quad(48.5-76.75)\end{array}$ & $41-73$ & $0.004^{\dagger}$ \\
\hline $\begin{array}{l}\text { ALB, median (IQR) } \\
(\mathrm{g} / \mathrm{l})\end{array}$ & $\begin{array}{l}30.0 \\
\quad(25.50-35.0)\end{array}$ & $\begin{array}{l}34.50 \\
\quad(29.0-40.0)\end{array}$ & $40-55$ & $0.001^{\dagger}$ \\
\hline
\end{tabular}


Table 4 continued

\begin{tabular}{lllll}
\hline Index & LMV & SLE & Normal range & $P$ value \\
\hline ALT, median (IQR) & $27.0(17.0-46.0)$ & 17.0 & $13-69$ & $0.004^{\dagger}$ \\
$\quad(\mathrm{U} / \mathrm{l})$ & $(13.0-29.0)$ & & \\
$\begin{array}{l}\text { AST, median (IQR) } \\
(\mathrm{U} / \mathrm{l})\end{array}$ & $30.0(22.0-56.0)$ & $\begin{array}{c}24.0 \\
(17.0-38.0)\end{array}$ & $15-46$ & $0.019^{\dagger}$ \\
\hline
\end{tabular}

$I Q R$ interquartile range, $S D$ standard deviation, $N$ number, $W B C$ white blood cells, $H G B$ hemoglobin, $P L T$ platelet, $N \%$ percentage of neutrophils, $L \%$ percentage of lymphocytes, $A N A(+)$ positive for titer of antinuclear antibody, Anti-dsDNA $A b$ (+), positive of anti-double-stranded DNA antibody, SSA anti-Ro antibody, $C$ complement, $D-D$ D-dimer, ESR erythrocyte sediment rate, CRP C-reactive protein, Cre creatinine, $A L B$ Albumin, $A L T$ alanine aminotransferase, $A S T$ aspartate transaminase

$\dagger$ Represents $P \leq 0.05$

Table 5 Associations of D-D, C3, and L\% with LMV

\begin{tabular}{lllllll}
\hline Indexes & $\boldsymbol{\beta}$ & $\boldsymbol{S E}$ & $\boldsymbol{\chi}^{\mathbf{2}}$ & $\mathbf{D F}$ & Adjusted OR(95\%CI) & $\boldsymbol{P}$ value \\
\hline OU & 1.446 & 0.641 & 5.082 & 1 & $4.25(1.208,14.926)$ & 0.024 \\
UTI & 1.655 & 0.718 & 5.310 & 1 & $5.23(1.281,21.387)$ & 0.021 \\
D-D & 0.115 & 0.043 & 7.147 & 1 & $1.121(1.031,1.220)$ & 0.008 \\
C3 & -3.035 & 1.144 & 7.039 & 1 & $0.048(0.005,0.453)$ & 0.008 \\
L\% & -0.075 & 0.026 & 8.298 & 1 & $0.928(0.882,0.976)$ & 0.004 \\
\hline
\end{tabular}

$S E$ standard error, $D F$ degrees of freedom, $U T I$ urinary tract involvement, $O U$ oral ulcers, $D-D$ D-dimer, $C$ complement, $L \%$ percentage of lymphocytes

\section{Associated Factors of Lupus Mesenteric Vasculitis (LMV) in Systemic Lupus Erythematosus (SLE) Patients}

\section{Comparison of Demographic and Clinical Features Between LMV and Non-LMV-SLE Patients}

Altogether, 50 LMV and 89 non-LMV-SLE patients were enrolled in the current study. Demographic and clinical information of LMV and non-LMV-SLE patients are summarized in Table 3. Notably, there was no statistical difference between the two groups regarding sex ratios, mean age and incidence of arthritis, neurologic involvement, fever, and edema. However, the LMV group showed a higher SLEDAI score than non-LMV-SLE, with 90\% (45/
50) of the LMV patients demonstrating SLEDAI scores higher than 10. Meanwhile, there were statistical differences between LMV and nonLMV-SLE concerning incidence of weight loss, skin rash, oral ulcers, alopecia, fatigue, and lupus urinary tract involvement. LMV patients more frequently suffered from oral mucosa ulcer than non-LMV-SLE controls (19/50, 38\% for LMV, and 12/89, 13.5\% for SLE).

\section{Comparison of Laboratory Characteristics Between LMV and SLE Patients}

As was shown in Table 4, there was no significant difference between LMV and non-LMV-SLE in aspects of white blood cell (WBC), hemoglobin (HGB), antinuclear antibody (ANA) titer, anti-double-stranded DNA antibodies (dsDNA), 
anti-La antibody (SSB), ribonucleoprotein (RNP), C-reactive protein (CRP), etc. However, the serum level of albumin (ALB) in LMV was significantly lower than that in SLE $(P=0.001)$. With regard to indexes of complete blood cell count (CBC), neutrophil percentage (N\%) in LMV was significantly higher than that in nonLMV-SLE $(P=0.002)$, while lymphocyte percentage (L\%) in LMV was significantly lower than that in SLE $(P<0.001)$.

Erythrocyte sedimentation rate (ESR) increased in both non-LMV-SLE and LMV groups, but it was relatively lower in LMV than in non-LMV-SLE. Similarly, serum levels of complement $3(\mathrm{C} 3)(P=0.007), \mathrm{C} 4(P=0.017)$, and IgG $(P<0.001)$ in LMV were considerably lower than in non-LMV-SLE. Besides, anti-Ro antibody (SSA) positivity in LMV was significantly higher than those in SLE $(P=0.02)$. Also, plasma concentration of D-dimer (D-D) $(P<0.001)$ and serum creatinine $(P=0.004)$ in LMV was notably higher than those in nonLMV-SLE. Importantly, concerning hepatic injury indexes, more LMV patients demonstrated abnormally elevated alanine aminotransferase (ALT) $(P=0.037)$ and aspartate transaminase (AST) $(P=0.047)$ than non-LMVSLE. Nevertheless, levels of serum $\gamma$-glutamyltransferase $(\gamma$-GGT) and alkaline phosphatase (ALP) showed no difference.

\section{Associated Factors of LMV}

Multivariable logistic analysis revealed that oral ulcers (OR, 4.25; $P=0.024)$, urinary tract involvement (OR, 5.23; $P=0.021)$ and elevated D-D (OR, 1.121; $P=0.008)$ were positively associated with occurrence of LMV, while C3 (OR, 0.048; $P=0.008$ ) and $\mathrm{L} \%$ (OR, 0.928; $P=0.004)$ were negatively associated factors for LMV (Table 5).

\section{DISCUSSION}

LMV is a rare but serious gastrointestinal complication in SLE patients presenting acute abdominal pain. The prevalence of LMV ranges from 0.2 to $9.7 \%$ in SLE patients $[2,11]$ and its incidence was $2.9 \%$ among hospitalized SLE patients in the current study. Generally, the manifestations of LMV were nonspecific. Most LMV patients complain of abdominal pain [20]. However, the pain degree and property vary from mild to severe, mimicking acute surgical abdomen. In the current study, many LMV patients were admitted to inappropriate departments and initially misdiagnosed as acute gastroenteritis, intestinal tuberculosis, peritoneal tuberculosis, urinary tract infection, urinary calculi, pancreatitis, and hepatitis because of its nonspecific symptoms and signs. Additionally, 26\% of LMV patients had LMV as onset without any SLE-related history [21]. The heterogeneity and lack of comprehensive understanding of LMV made prompt and accurate diagnosis of LMV a big challenge. Therefore, it is demanding to explore associated factors of LMV.

This study aimed to explore the possible associated factors of LMV. We demonstrated that oral ulcers could be an associated factor of LMV. Oral ulcers are the most common noninfectious and non-traumatic oral mucosal ulcerative disorders and are relevant to systemic disorders [22]. Also, aphthous ulcer is an important evaluating indicator in SLEDAI [23], and oral ulcerations could foretell a severe systemic disease flare [24]. A nationwide population-based study in Korea has demonstrated that oral ulcers were associated with an increased risk of systemic autoimmune diseases including SLE, and this study indicated that oral ulcers could be an early manifestation of systemic autoimmune disease [25]. Meanwhile, persistent palatal ulcerations could be a potential sign of SLE in adolescents [26]. We identified that the incidence of LMV in SLE patients with oral ulcers was four times those without oral ulcers. To avoid LMV, physicians should be cautious when oral ulcers appear in patients with SLE and provide a strategy for clinical treatment and precaution.

Meanwhile, urinary tract involvement was as another independent associated factor of LMV. Urinary tract involvement was reported to occur in $0.5-1.0 \%$ of SLE patients. We found that SLE patients accompanied with lupus urinary tract involvement had a fivefold greater risk of encountering LMV. Several studies reported that lupus bowel involvement was frequently 
associated with lupus urinary tract impairment [27-29]. The associations between urinary tract lesions and LMV had successfully triggered a serial of scientific assumption and exploration. Though the specific relationship and mechanism between lupus urinary tract impairment and LMV are still unrevealed, some scholars proposed that this was caused by vasculitis and anti-smooth muscle antibody, which was shared by gastrointestinal wall and bladder $[30,31]$. Therefore, clinicians should suspect the possibility of LMV when clinico-laboratory results suggested lupus involvement of urinary system.

Interestingly, we demonstrated that LMV patients got significantly lower levels of L\% than SLE, and reduced L\% was an independent associated factor of LMV. To our knowledge, this finding has not been reported in the literature. It is well known that lymphopenia is one of the clinical parameters used to assess disease activity in the Systemic Lupus Activity Measure (SLAM) [23]. In addition, previous studies reported a higher rate of T-lymphocyte (especially the CD4 + T-lymphocyte) apoptosis in active SLE patients and that T-lymphocyte apoptosis was directly correlated with lupus activity [32, 33]. These findings suggested that there was significant correlation between a higher ratio of T-lymphocyte apoptosis and lupus activity. It is a peripheral blood marker that is easy to monitor and operate. Thus, L\% could be applied as a preliminary screen test for SLE patients. Other examinations such as endoscopy and CT scan should be recommended for SLE patients with reduced L\% and GI symptoms or signs.

Complement activation was the essential mechanism of immune-complex-mediated mesenteric vasculitis [2]. Multiple clinical studies reported that serum levels of $\mathrm{C} 3$ and $\mathrm{C} 4$ were rather lower in LMV patients [6, 11,34], and the decrease of $\mathrm{C} 3$ was correlated with the clinical progression of LMV [34]. This study demonstrated that reduced C3 was an associated factor of LMV. So continuous hypocomplementemia of C3 could be helpful for clinical recognition of LMV in SLE patients.

It is widely acknowledged that thrombotic is one of the pivotal pathological mechanisms of
LMV $[2,35,36]$. SLE patients with normal D-D levels are at low risk for thrombosis, however, those with persistent unexplained elevated D-D levels are at high risk for thrombosis [37]. The current study proved that elevated D-D could be an associated factor of LMV. Elevated D-D levels have been reported as a strong factor of SLEinduced abdominal pain $[6,37]$. Therefore, the plasm level of D-D should be closely evaluated and precisely regulated to prevent the onset of LMV.

The present study has its own limitations. This study is a single-centered retrospective investigation, suggesting potential selection bias and small sample size are objective existence. In the future, multicentered, prospective, and long-term follow-up studies will be necessary to confirm our findings.

In conclusion, LMV could occur at any stage of SLE. Most of the LMV patients could achieve clinical remission after appropriate treatment. When SLE patients present with abdominal pain or abdominal tenderness and with oral ulcers, urinary tract involvement, reduced lymphocytes, C3 or elevated D-D should be highly suspected of LMV. On the other side, SLE patients should be informed to note the five factors, changes of them may forebode the onset risk of LMV.

\section{ACKNOWLEDGEMENTS}

Editorial assistance in the preparation of this article was provided by Dr. Shifeng Huang (Department of Laboratory Medicine, The First Affiliated Hospital of Chongqing Medical University). We thank Dr. Mengqi Liu (Department of Radiology, The First Affiliated Hospital of Chongqing Medical University) and Dr. Yu Zhong (Department of Integrated Chinese and Western Medicine, The First Affiliated Hospital of Chongqing Medical University) for reviewing the imaging data and medical data, respectively.

Funding. This study was supported by The Cultivating fund of The First Affiliated Hospital of Chongqing Medical University (Grant 
Number: PYJJ2018-09). The journal's Rapid Service Fee was funded by the authors.

Authorship. All named authors meet the International Committee of Medical Journal Editors (ICMJE) criteria for authorship for this article, take responsibility for the integrity of the work as a whole, and have given their approval for this version to be published.

Authorship Contributions. Wenxian You and Gao Qing designed this cohort study. Guanyi Liao and Sirui Ren gathered the clinical records of both LMV and SLE. Hongxu Wang and Wenxian You performed statistical analysis together. Hongxu Wang wrote the manuscript and all authors reviewed the manuscript.

Disclosures. Hongxu Wang, Gao Qing, Guanyi Liao, Sirui Ren, and Wenxian have nothing to disclose.

Compliance with Ethics Guidelines. This study was performed in accordance with the Helsinki Declaration of 1964, and its later amendments. This retrospective study was reviewed and approved by the Ethics Committee of The First Affiliated Hospital of Chongqing Medical University. For this type of study, formal consent is not required.

Data Availability. The datasets generated during and/or analyzed during the current study are available from the corresponding author on reasonable request.

Open Access. This article is licensed under a Creative Commons Attribution-NonCommercial 4.0 International License, which permits any non-commercial use, sharing, adaptation, distribution and reproduction in any medium or format, as long as you give appropriate credit to the original author(s) and the source, provide a link to the Creative Commons licence, and indicate if changes were made. The images or other third party material in this article are included in the article's Creative Commons licence, unless indicated otherwise in a credit line to the material. If material is not included in the article's Creative
Commons licence and your intended use is not permitted by statutory regulation or exceeds the permitted use, you will need to obtain permission directly from the copyright holder. To view a copy of this licence, visit http:// creativecommons.org/licenses/by-nc/4.0/.

\section{REFERENCES}

1. Kaul A, Gordon C, Crow MK, Touma Z, Urowitz MB, van Vollenhoven R, et al. Systemic lupus erythematosus. Nat Rev Dis Primers. 2016;2:16039.

2. Ju JH, Min JK, Jung CK, Oh SN, Kwok SK, Kang KY, et al. Lupus mesenteric vasculitis can cause acute abdominal pain in patients with SLE. Nat Rev Rheumatol. 2009;5(5):273-81.

3. Tian XP, Zhang X. Gastrointestinal involvement in systemic lupus erythematosus: insight into pathogenesis, diagnosis and treatment. World J Gastroenterol. 2010;16(24):2971-7.

4. Fawzy M, Edrees A, Okasha H, El Ashmaui A, Ragab G. Gastrointestinal manifestations in systemic lupus erythematosus. Lupus. 2016;25(13):1456-62.

5. Sonmez HE, Karhan AN, Batu ED, Bilginer Y, Gumus E, Demir H, et al. Gastrointestinal system manifestations in juvenile systemic lupus erythematosus. Clin Rheumatol. 2017;36(7):1521-6.

6. Yuan S, Lian F, Chen D, Li H, Qiu Q, Zhan Z, et al. Clinical features and associated factors of abdominal pain in systemic lupus erythematosus. J Rheumatol. 2013;40(12):2015-22.

7. Ha HK, Lee SH, Rha SE, Kim JH, Byun JY, Lim HK et al. Radiologic features of vasculitis involving the gastrointestinal tract. Radiographics : a review publication of the Radiological Society of North America, Inc. 2000;20(3):779-94.

8. Ko SF, Lee TY, Cheng TT, Ng SH, Lai HM, Cheng YF, et al. CT findings at lupus mesenteric vasculitis. Acta Radiol. 1997;38(1):115-20.

9. Janssens P, Arnaud L, Galicier L, Mathian A, Hie M, Sene D, et al. Lupus enteritis: from clinical findings to therapeutic management. Orphanet J Rare Dis. 2013;8:67.

10. Maruyama A, Nagashima T, Iwamoto M, Minota S. Clinical characteristics of lupus enteritis in Japanese patients: the large intestine-dominant type has features of intestinal pseudo-obstruction. Lupus. 2018;27(10):1661-9. 
11. Yuan S, Ye Y, Chen D, Qiu Q, Zhan Z, Lian F, et al. Lupus mesenteric vasculitis: clinical features and associated factors for the recurrence and prognosis of disease. Semin Arthritis Rheum. 2014;43(6): 759-66.

12. Byun JY, Ha HK, Yu SY, Min JK, Park SH, Kim HY, et al. CT features of systemic lupus erythematosus in patients with acute abdominal pain: emphasis on ischemic bowel disease. Radiology. 1999;211(1): 203-9.

13. Endo H, Kondo Y, Kawagoe K, Ohya TR, Yanagawa $\mathrm{T}$, Asayama M, et al. Lupus enteritis detected by capsule endoscopy. Intern Med. 2007;46(18): 1621-2.

14. Tu YL, Yeh KW, Chen LC, Yao TC, Ou LS, Lee WI, et al. Differences in disease features between childhood-onset and adult-onset systemic lupus erythematosus patients presenting with acute abdominal pain. Semin Arthritis Rheum. 2011;40(5):447-54.

15. Si-Hoe CK, Thng CH, Chee SG, Teo EK, Chng HH. Abdominal computed tomography in systemic lupus erythematosus. Clin Radiol. 1997;52(4): 284-9.

16. Hochberg MC. Updating the American College of Rheumatology revised criteria for the classification of systemic lupus erythematosus. Arthritis Rheum. 1997;40(9):1725.

17. Petri M, Orbai AM, Alarcon GS, Gordon C, Merrill JT, Fortin PR, et al. Derivation and validation of the Systemic Lupus International Collaborating Clinics classification criteria for systemic lupus erythematosus. Arthritis Rheum. 2012;64(8):2677-86.

18. Tan EM, Cohen AS, Fries JF, Masi AT, McShane DJ, Rothfield NF, et al. The 1982 revised criteria for the classification of systemic lupus erythematosus. Arthritis Rheum. 1982;25(11):1271-7.

19. Gladman DD, Ibanez D, Urowitz MB. Systemic lupus erythematosus disease activity index 2000. J Rheumatol. 2002;29(2):288-91.

20. Alsalameh S, Hauggaard A. Mesenteric vasculitis in active systemic lupus erythematosus causing diffuse abdominal pain. Rheumatol (Oxf). 2013;52(10): 1889.

21. Liu Y, Zhu J, Lai JM, Sun XF, Hou J, Zhou ZX, et al. Reports of three cases with the initial presentation of mesenteric vasculitis in children with system lupus erythematous. Clin Rheumatol. 2018;37(1): 277-83.

22. Porter SR, Leao JC. Review article: oral ulcers and its relevance to systemic disorders. Aliment Pharmacol Ther. 2005;21(4):295-306.
23. Romero-Diaz J, Isenberg $\mathrm{D}$, Ramsey-Goldman R. Measures of adult systemic lupus erythematosus: updated version of British Isles Lupus Assessment Group (BILAG 2004), European Consensus Lupus Activity Measurements (ECLAM), Systemic Lupus Activity Measure, Revised (SLAM-R), Systemic Lupus Activity Questionnaire for Population Studies (SLAQ), Systemic Lupus Erythematosus Disease Activity Index 2000 (SLEDAI-2K), and Systemic Lupus International Collaborating Clinics/American College of Rheumatology Damage Index (SDI). Arthritis Care Res. 2011;63(Suppl 11):S37-46.

24. Jorizzo JL, Salisbury PL, Rogers RS, Goldsmith SM, Shar GG, Callen JP, et al. Oral lesions in systemic lupus erythematosus. Do ulcerative lesions represent a necrotizing vasculitis? J Am Acad Dermatol. 1992;27(3):389-94.

25. Lee YC, Jeong SJ, Eun YG, Song R, Oh IH. Risk of autoimmune diseases in recurrent aphthous ulcer patients: a nationwide population study. Oral Dis. 2020;26:1-8.

26. Katz J, Islam MN, Cha S, Saleh W, Guelmann M. Persistent palatal ulcerations. A potential manifestation of juvenile systemic lupus erythematosus. J Clin Pediatr Dent. 2020;44(1):52-4.

27. Chu YC, Hsu BB, Tseng KC. Lupus mesenteric vasculitis with GI and genitourinary tract involvement. Clin Gastroenterol Hepatol. 2014;12(8):e6970.

28. Shimizu A, Tamura A, Tago O, Abe M, Nagai Y, Ishikawa O. Lupus cystitis: a case report and review of the literature. Lupus. 2009;18(7):655-8.

29. Tan TC, Wansaicheong GK, Thong BY. Acute onset of systemic lupus erythematosus with extensive gastrointestinal and genitourinary involvement. Lupus. 2012;21(11):1240-3.

30. $\mathrm{Xu} \mathrm{D,} \mathrm{Lin} \mathrm{J.} \mathrm{Urinary} \mathrm{tract} \mathrm{involvement} \mathrm{in} \mathrm{systemic}$ lupus erythematosus: coexistence with lupus mesenteric vasculitis or intestinal pseudo-obstruction? Semin Arthritis Rheum. 2015;44(4):e9.

31. Koh JH, Lee J, Jung SM, Ju JH, Park SH, Kim HY, et al. Lupus cystitis in Korean patients with systemic lupus erythematosus: risk factors and clinical outcomes. Lupus. 2015;24(12):1300-7.

32. Dhir V, Singh AP, Aggarwal A, Naik S, Misra R. Increased T-lymphocyte apoptosis in lupus correlates with disease activity and may be responsible for reduced T-cell frequency: a cross-sectional and longitudinal study. Lupus. 2009;18(9):785-91.

33. Shah D, Aggarwal A, Bhatnagar A, Kiran R, Wanchu A. Association between $\mathrm{T}$ lymphocyte sub-sets apoptosis and peripheral blood mononuclear cells 
oxidative stress in systemic lupus erythematosus. Free Radical Res. 2011;45(5):559-67.

34. Chen SY, Xu JH, Shuai ZW, Wang MQ, Wang F, Xu $\mathrm{SQ}$, et al. A clinical analysis 30 cases of lupus mesenteric vasculitis. Zhonghua Nei Ke Za Zhi. 2009;48(2):136-9.

35. Uhrenholt L, Jensen LS, Jakobsen TS, Kristensen S, Dahlerup JF, Pahle E, et al. Acute abdominal vasculitis in rheumatic diseases. Ugeskr Laeger. 2018;180:24.

36. Barile-Fabris L, Hernandez-Cabrera MF, BarraganGarfias JA. Vasculitis in systemic lupus erythematosus. Curr Rheumatol Rep. 2014;16(9):440.

37. Wu H, Birmingham DJ, Rovin B, Hackshaw KV, Haddad N, Haden D, et al. D-dimer level and the risk for thrombosis in systemic lupus erythematosus. Clin J Am Soc Nephrol. 2008;3(6):1628-36. 